\title{
Teaching Health Promotion: EXPERIENCES FROM THE UNIVERSITY OF THE WESTERN CAPE
}

\begin{abstract}
This article describes and assesses the University of the Western Cape's (UWC) second year Community and Health Science students' experience in their interdisciplinary, community based health promotion module. Health promotion is a rapidly growing discipline for health professionals internationally. The World Health Organisation (WHO) has described health promoting schools as effective settings for the promotion of the health of learners, teachers, parents and the broader community. The health promotion module at UWC introduces the university students to the practical development of health promoting schools. The aim of this study was to assess undergraduate students' attitudes to and impressions of their learning experience during the health promotion module. These interventions included addressing teenage pregnancy; addressing drug abuse including smoking; addressing poor personal hygiene; and addressing the poor classroom environment. Small interdisciplinary teams of students worked with school learners at a high school in a poorly resourced area in Cape Town, where they planned, implemented and evaluated small scale interventions. Students indicated they had learnt far more from the interdisciplinary, experiential learning than from classroom based learning or textbooks located within their own discipline. The results suggest that health promotion is an ideal subject for physiotherapy students to study collaboratively with the other health disciplines. One group of students wrote: "We have learnt much more than any textbook or lecturer could ever teach us."
\end{abstract}

KEY WORDS: HEALTH PROMOTION; INTERDISCIPLINARY LEARNING; COMMUNITY BASED EDUCATION; HEALTH PROMOTING SCHOOLS; PHYSIOTHERAPY.

\section{INTRODUCTION}

This article describes and assesses how we are teaching health promotion to second year undergraduate physiotherapy students at the University of the Western Cape (UWC) in Cape Town, South Africa.

Health promotion is an area of increasing growth for physiotherapists internationally, but is, however, still a relatively new field and one that is still opening up in South Africa. It is considered an essential part of the training of all health care students at UWC. As a result of a decision made by the Community and Health Science Faculty, an interdisciplinary module in health promotion has been developed for undergraduate students. The purpose of the health promotion module is, firstly, for students to plan, implement and evaluate a small health promotion project, and secondly for students to understand the value of implementing health promotion in a setting by using the "health promoting schools" framework (WHO, 1995).
The health promoting schools framework is based on the principles of health promotion contained in the Ottawa Charter which were put forward by the World Health Organisation (WHO) in 1986:

- Building healthy public policies

- Creating supportive environments

- Developing personal skills

- Strengthening community action

- Reorienting the health services

The development of health promotion in particular settings involves combining all these principles. Health promoting settings include "healthy cities", "health promoting hospitals", and "health promoting schools" (Tones \& Tilford, 2001).

At the Fourth International Health Promotion Conference in Jakarta, in 1997, the World Health Organisation stated that health promoting schools are effective settings for the promotion of health. Learners, teachers, and other staff who work in schools as well as parents and the community members who they link with, are all positively affected by the development of a health promoting school (WHO, 1997a). "A health promoting school can be characterized as a school that is constantly strengthening its capacity as a healthy setting for living, learning and working" (WHO, 1997b). Health promoting schools focus on developing an environment that is safe and enhances health, as well as encouraging learners and teachers to follow healthy lifestyles which promote their health.

In South Africa the Departments of Health, Education and Welfare (Depart-

\section{CORRESPONDENCE TO:}

Struthers Patricia

Physiotherapy Department

University of the Western Cape

Private Bag X17

Bellville 7975

(021) 959-2542 (work)

(021) 686-3601 (home)

082 202-3161

pstruthers@uwc.ac.za 
ment of Health, 2000) have developed guidelines for the development of health promoting schools. The increased participation of schools that identify themselves as health promoting schools has been particularly good in the Western Cape with over 100 schools now linked to the Western Cape Health Promoting Schools Reference Group a network of health promoting schools.

In 2002 the development of health promoting schools became the focus of the practical component of the UWC health promotion module. Community based education, an effective learning experience (Mpofu, 1999), is used in this module. At the time of this study, the module was run over seven weeks with a weekly one-hour classroom based session for theoretical input, and a two-hour practical health promotion session in a local school. In addition the students met in smaller teams on a regular basis to plan activities for the school and, individually, the students were required to do additional reading. The purpose of the practical sessions was for university students and school learners to be involved in an appropriate health promotion intervention that would contribute towards the development of the school as a health promoting school. Students used a simple planning cycle involving a needs analysis; planning of an appropriate intervention; implementation; and finally evaluation of their intervention. In designing their intervention, the students drew from different health promotion models including the health belief model and social learning theory.

\section{AIM OF STUDY}

To assess undergraduate students' attitudes to and impressions of their learning experience during the health promotion module.

\section{METHODOLOGY}

Qualitative research methodology based on grounded theory was used in this study (Creswell, 1998). This is a design that explains phenomena grounded in reality, in this instance the learning experience of the students. It is a research design where data may be drawn from documents, in this instance the students' reflective journals and assignments. The subjects included 36 second-year university students from the departments of physiotherapy, nursing, psychology and occupational therapy. The students were divided into smaller interdisciplinary teams with six students in each team. The study setting was a high school in a poorly resourced, urbanized area $10 \mathrm{~km}$ from the university (about 35 $\mathrm{km}$ outside of Cape Town). The school had 938 learners and 30 teachers. Each team worked with a class of approximately 35 learners from Grades 8-10. For safety and practical purposes the university organised a bus to transport all students to and from the school. One or two university staff facilitators were present at the school at all times. The research instruments included observation and data obtained from students' weekly reflective journals and team assignments. The reflective journals (Baker, 1996) described students' experience in the school; their analysis of the significance of the experience; and the broader implication for their learning as a human being. These journals were written weekly at the end of each practical session. The team assignments described the health promotion intervention including the situation analysis planning and their evaluation of the learners' experience of the intervention. The qualitative analysis involved coding the data and identifying the themes that emerged (Creswell, 1998). The researcher and the second staff facilitator discussed the data and coding to ensure trustworthiness. The use of both observation and documentation also helped ensure trustworthiness. Ethical considerations included getting permission from the students to use the data and ensuring their confidentiality. The school, learners and teachers are not identified for confidentiality. Permission to work in the school was obtained from the Western Cape Education Department.

\section{RESULTS}

Three major themes, relating closely to the aim of assessing the students' attitudes to and impressions of their learning experience, emerged from the data: firstly, the effect of the learning leading to changes in the students themselves; secondly, the importance of the school environment including a healthy environment and the problems related to safety; and, thirdly, the personal difficulties experienced by the learners and teachers.

\section{Changes students experienced in themselves}

One team of students wrote about feeling "very confused" and "unsure" of their purpose at the beginning of the module but at the end wrote: "We have planted seeds and hopefully those seeds will grow ... We have learnt much more than any textbook or lecturer could ever teach us".

Another team wrote: "Upon our arrival there were many learners hanging out of the windows shouting at us. This made us really worried because we did not think we would have their cooperation." However, later, they wrote about having learnt a lot, and felt the learners had also grown: "The health promotion project was a very meaningful and fulfilling experience for $u s$ as human beings and future health professionals. We did not anticipate this project to be a reciprocal learning experience, we learned just as much from them, as they from us."

Students described how they had experienced learners beginning to trust them and how much this had enabled them to learn. They reflected on how empowerment cannot be imposed on others but grows from within: "I discovered that you can't go into an environment and expect a person to trust you, especially teenagers. I have learnt so much about people from the time I have entered university, but the last two visits made me open my eyes and now I am really getting to know how to understand someone. It is not about myself and my marks anymore. It's about them and how I can enrich their lives and give them some hope, and to teach them that they are the only ones who can make a difference in their lives."

The experience in the school opened the eyes of many students to poverty and how the effect of poverty in the whole community was reflected in the school. "The whole experience was an eye opener for me. When people used to talk about previously disadvantaged 
groups of people, I never understood fully the concept." The experience of getting to know learners from a different socioeconomic background helped students overcome stereotyping people. They became critical of the government for not doing enough for the learners at this school.

Overall, it was described as an enriching learning experience, with students gaining self-confidence through their active participation in the project "I feel I have grown as a human being in the past six weeks. I feel fortunate that I have been given this experience, to see what life for many South Africans is like apart from my cotton wool existence."

\section{Importance of a healthy school environment}

Prior to visiting the school, one of the teachers came to the university and described the school to the students: "It is a badly vandalized school in a ganginfested area. The learners at the school experience major social problems at home." As a result many of the university students were anxious before going to the school. Their first impressions of the school reinforced their fears, as one student wrote in her learning journal at the end of the first practical session: "The school felt and looked more like a prison than an institution of learning".

Students were shocked by the conditions that many young people are expected to learn in. There was graffiti all over the walls and vandalism had resulted in damage to the school's appearance. "School for these learners is not a very happy place. It's more like a place just to waste time or play around, but definitely not a place to be at for education." Another student wrote: "Once we were there and it was a cold and rainy day. I could feel that icy wind through those empty window frames and sand blowing in. A section of the class can sometimes not be used because it rains or the wind blows the paper or books apart." Almost all the windows were broken resulting in cold classrooms in winter. There was no electricity in the classrooms. As another student wrote, "The school is dilapidated, many windows are terribly broken. The doors to the classroom have no handles." There were no sports facilities at the school.
Students reflected on how the school environment made it impossible for effective learning to take place. "By now they're probably used to these horrible and sad conditions, but no child or learner can perform sufficiently or efficiently under these circumstances."

\section{Safe schools}

Safety is a major problem in many schools on the Cape Flats. The students found factors related to safety affected them planning the health promotion intervention. Regular visits to the school were not always possible. On one occasion a local community member threw a petrol bomb into a classroom in the early hours of the morning. The school was declared physically unsafe by the fire brigade and the visit had to be cancelled. Teachers and learners reported that gangsters had free access to the school as the boundary fence had been vandalized. Students reported that learners were afraid, feeling their lives were in danger. "The learners fear for their lives - due to the gangsters moving in and out of the school so freely." Another student stated: "I was having feelings of not being safe because the pupils told us that sometimes gangsters come to the school and shoot guns." Teachers indicated that they felt threatened by learners, some of whom were linked to the local gangs.

\section{Learners' difficulties}

Students described how some of the learners spoke to them about sexual harassment. Teenage pregnancy was identified as a big problem, as the girls were unable to return to school after giving birth. One teacher remarked: "This school is referred to by the community as 'the maternity ward [of this community]'”. The learners spoke of substance abuse in particular dagga being smoked in breaks and in class when the teacher was away. Tobacco smoking was common. Personal hygiene was poor. Many learners played truant and others came to school hungry as they had very little food at home.

\section{Teachers' difficulties}

Teachers spoke to the students about how low the morale was in the school. Many teachers were absent from school on a regular basis. They spoke of poor discipline amongst the learners and learners having little respect for the teachers. Learners complained of teachers being drunk at school and not attending classes.

\section{DISCUSSION}

The results indicate that an interdisciplinary, community based approach in teaching health promotion is an effective teaching method. Papa et al., (1998) describe how conflict can arise with interdisciplinary learning as a result of attempting to work on an equal basis while simultaneously trying to protect ones professional turf. This did not happen with the UWC students, possibly because the topic for the intervention that each team focused on was selected following an effective participatory process with the school learners. These interventions included addressing teenage pregnancy; addressing drug abuse including smoking; addressing poor personal hygiene; and addressing the poor classroom environment. The health promotion intervention was "owned" by all students not those from one discipline over another. Secondly, the module is "housed" in the faculty office and not in a specific department. The teaching emphasised drawing on one another's strengths and skills learnt in each student's home discipline.

One practical problem with the interdisciplinary teamwork was that students from different disciplines found it difficult to find time when they could all meet together on a regular basis. At times this led to reduced participation of some students resulting in their dissatisfaction while other students resented their absence. Despite this the students gained management skills, communication skills and skills in group-dynamics.

The experience of working in the community, listening to the needs of the learners and the teachers opened the eyes of many students. They recognised the need for health promotion to go beyond a focus on changing the individual learner's behaviour, for example, improving hygiene or stopping the use of drugs at school, but also needed to change the school environment. By working with learners in the school they 
could identify problems in the classroom environment; the school environment, for example no sports facilities and absence of a perimeter fence; and the broader community for example poverty, and gangsterism. One student suggested a more holistic intervention could be to involve the whole school and the community in a fun day, to start building the links between the school and the community. However, there was insufficient time to implement this.

The value of linking schools to the Western Cape Health Promoting Schools Reference Group is that schools with few resources can get support from schools with more resources in the form of experience and support. Many schools have developed healthy policies and have well established links with the community. Unfortunately there was insufficient time for the university students to experience this process.

There are some limitations with the community based learning experience. Seven weeks is a very short time, making it difficult to include all aspects of health promotion including both environmental change and lifestyle change. It was not possible for students to be involved in the development of healthy school policies or linking with the community. We disrupted the high school routine and the teachers were not sufficiently involved. Finally, the effect on the students of the health promotion module and the experience of being in the schools has not been evaluated over a longer period since completing the module.

A question that is difficult to answer is: "Did the students' small interventions help to build a health promoting school?" Many teachers in South Africa are experiencing a great deal of stress related to their work in the schools. At this school, some teachers spoke of how they found the experience of having university students coming into the school positive. One teacher, whose classroom had been cleaned, painted and decorated, desks sanded and varnished, and graffiti removed from cupboards by students and learners, remarked that the students had brought "a new spirit" and enthusiasm into her class and into the school. "Yes" is the answer. As a result of the students' interventions some of the teachers were more motivated and initiated moves to become more involved in the health promoting schools network in the Western Cape.

\section{CONCLUSION}

Interdisciplinary learning was an effective and enriching experience for the undergraduate physiotherapy students at UWC with all the students taking part in planning, implementing and evaluating a health promotion project. As one student described "I believe we cannot wait for the politicians or the government to take action, we have to act if we want to change the direction in which this country is heading”. Another student said "They [the learners] have given me hope, not only us giving them. They have given me hope that we can make a difference and that they actually want help."

This study suggests an interdisciplinary approach to the teaching of health promotion is an effective method for physiotherapy students to learn health promotion skills including advocacy, empowerment and mediation. It is also an ideal opportunity for health professional students to learn through combining health promotion and community based education.

\section{ACKNOWLEDGEMENTS}

The financial assistance of VLIR towards this paper is hereby acknowledged. Opinions expressed in this paper and conclusions arrived at are mine and not necessarily to be attributed to the funder.

\section{REFERENCES}

Baker C 1996 Reflective learning: A teaching strategy for critical thinking. Journal of Nursing Education 35:19-22

Creswell J 1998 Qualitative inquiry and research design: choosing among five traditions. SAGE Publications, London

Department of Health 2000 Draft National Guidelines for the Development of Health Promoting Schools/sites in South Africa. Department of Health, Pretoria

Mpofu R 1999 The community as basis for the initial training of therapists: A curriculum development study. Unpublished doctoral thesis. University of the Western Cape, Bellville, South Africa

Papa P, Rector C, Stone C 1998 Interdisciplinary collaborative training for schoolbased health professionals. Journal of School Health 68:415-420

Tones K, Tilford S 2001 Health Promotion: effectiveness, efficiency and equity, 3rd edn. pp 195-219. Chapman and Hall, Cheltenham, United Kingdom

World Health Organisation (WHO) 1995 Global school health initiative: A call to action. WHO, Geneva

World Health Organisation (WHO) 1986 Ottawa Charter, First international conference on Health Promotion. WHO, Geneva

World Health Organisation 1997a The Jakarta Declaration on leading health promotion into the 21st Century. WHO, Geneva

World Health Organisation 1997b The Health Needs of Adolescents, Report of a WHO Expert Committee, Technical Report Series 308. WHO, Geneva 